\title{
ANALISIS ALTERNATIF PERANCANGAN DESAIN DALAM PEMBANGUNAN JALAN DI ATAS TANAH GAMBUT
}

\author{
Fendy Hartanto ${ }^{1}$ dan Chaidir Anwar Makarim ${ }^{2}$ \\ ${ }^{1}$ Program Studi Sarjana Teknik Sipil, Universitas Tarumanagara, Jl. Letjen S. Parman No.1 Jakarta \\ Fendy.325160138@stu.untar.ac.id \\ ${ }^{2}$ Program Studi Sarjana Teknik Sipil, Universitas Tarumanagara, Jl. Letjen S. Parman No.1 Jakarta \\ Chaidir259@gmail.com
}

Masuk: 30-06-2020, revisi: 16-07-2020, diterima untuk diterbitkan: 04-08-2020

\begin{abstract}
The construction of the new capital city will be carried out in Kalimantan where there is a lot of land covered with peat soils. Peat soils might cause a lot of problems during construction projects, because peat soils usually have a weak shear strength and high permeability. In this case there will be a road construction with width of 12 meters and length of 20 meters on peat soils. To overcome this problem there are some solutions by using piles until it reached its needed bearing capacity or soil replacement, because not only its increasing its strength but it also prevent peat soils from catching fire since dry peat soils is quite flammable which happens in dry weather. From these methods there are advantages and disadvantages and will be analised which methods is better to be done for this road construction that is on peat soils. Calculations for piles will be done with program PLAXIS 2D to get the total displacements FROM the number of piles and dimensions, soil replacements will be counted by its soil volume that need to be replaced. The results will be reference to conclude which methods will be most suitable for this case.
\end{abstract}

Keywords: peat soils; piles; soil replacement; construction; road

\begin{abstract}
ABSTRAK
Pembangunan ibu kota baru akan dilaksanakan di Kalimantan dimana disana terdapat banyak sekali tanah gambut. Tanah gambut bisa menjadi masalah ketika kita sedang melakukan pembangunan konstruksi karena tanah gambut biasanya memiliki kekuatan geser yang kecil dan permeabilitas yang tinggi. Pada kasus kali ini akan dibangun jalan selebar 12 meter dengan panjang 20 meter yang terdapat tanah gambut dibawahnya. Untuk mengatasi masalah tanah gambut ini bisa diterapkan beberapa metode yaitu dengan memancang di tanah gambut dengan tiang pancang hingga mencapai tanah keras yang berada dibawahnya, soil replacement juga bisa menjadi suatu solusi karena selain membuang tanah gambut itu sendiri yang dimana cukup berbahaya dikarenakan mudah terbakar ketika musim kering, tetapi juga meningkatkan kekuatan dari daya dukung tanah itu sendiri. Dari kedua metode tersebut memiliki kelebihan dan kekurangan masing-masing dan akan dianalisis metode apa yang lebih baik dan sesuai dalam membangun konstruksi jalan yang melintasi tanah gambut sepanjang 20 meter. Perhitungan tiang pancang menggunakan program PLAXIS 2D untuk membantu mendapatkan nilai total penurunan dan jumlah tiang dan ukuran yang dibutuhkan dan untuk metode soil replacement akan dihitung volume tanah yang akan dikeruk dan ditimbum Kembali. Hasil pengolahan data dari perhitungan akan menjadi acuan sebagai pembanding metode apa yang sesuai dalam kasus kali ini.
\end{abstract}

Kata Kunci: tanah gambut; tiang pancang; soil replacement; konstruksi; jalan

\section{PENDAHULUAN}

Masalah pada tanah gambut sering menimbulkan kendala pada konstruksi maupun itu bangunan atau jalan, lahan tanah gambut memiliki sifat kekuatan geser yang rendah dan permeabilitas yang cukup tinggi sehingga menimbulkan kendala pada pembangunan. Terdapat beberapa metode perbaikan tanah untuk mengatasi masalah dari lahan gambut ini seperti menggunakan tiang pancang. Tanah gambut berserat mempunyai sifat fisik yang kurang baik (Yulianto \& Mochtar, 2010); yaitu: kadar air yang tinggi (500\%-900\%), angka pori yang besar (7-15) dan spesific gravity yang rendah (1.2 - 1.6). Akibatnya tanah gambut berserat juga mempunyai daya dukung yang rendah $(5-7 \mathrm{kPa})$ dan mempunyai pemampatan yang besar dan tidak merata (Jelisic \& Leppanen, 2001). Sehingga tanah gambut akan memberikan masalah jika dijadikan fondasi bagi bangunan sipil jika tidak dilakukan perbaikan tanah. 


\section{Tanah gambut}

Tanah gambut berserat mempunyai sifat fisik yang kurang baik (Yulianto \& Mochtar, 2010); yaitu: kadar air yang tinggi (500\%-900\%), angka pori yang besar (7-15) dan spesific gravity yang rendah (1.2 - 1.6). Akibatnya tanah gambut berserat juga mempunyai daya dukung yang rendah $(5-7 \mathrm{kPa})$ dan mempunyai pemampatan yang besar dan tidak merata (Jelisic \& Leppanen, 2001). Sehingga tanah gambut akan memberikan masalah jika dijadikan fondasi bagi bangunan sipil jika tidak dilakukan perbaikan tanah.

Tanah gambut memiliki sifat yang cukup berbahaya, seperti mudah terbakarnya tanah gambut ketika musim panas. Hal ini dikarenakan tanah gambut memiliki sifat irreversible drying (kering tidak balik) dimana ketika tanah gambut menjadi kering tanah gambut kehilangan kemampuan untuk menyerap air lagi, pada kondisi ini tanah gambut menjadi mudah terbakar dan mudah hanyut terbawa oleh air.

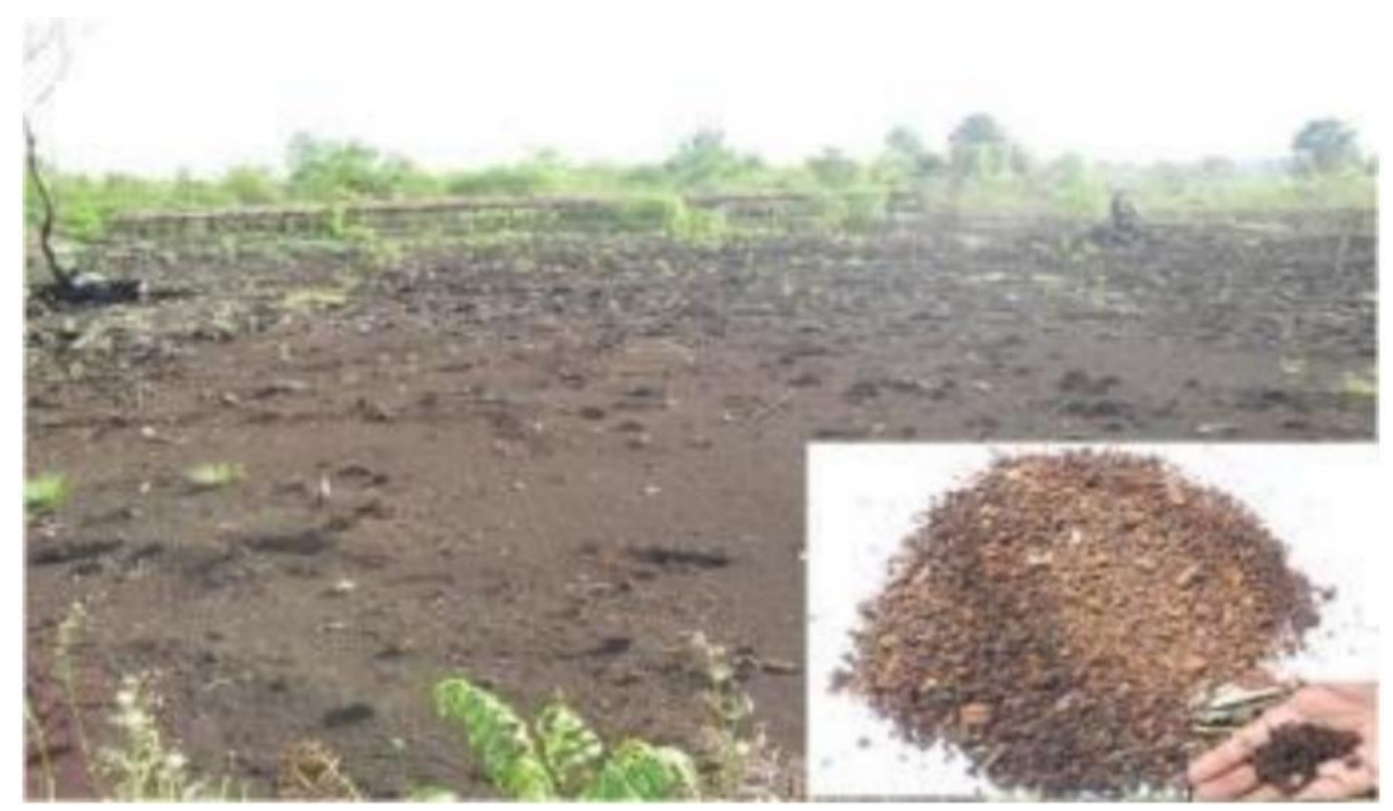

Gambar 1. Kondisi tanah gambut yang telah mengalami kering tak balik membentuk pasir semu yang tidak mampu lagi menyerap air (Sumber: Dariah dan Maftuah, 2011)

Tabel 1. Parameter tanah gambut di Indonesia

\begin{tabular}{ccccc}
\hline Parameter & Satuan & Banjarmasin & Palangkaraya & Pekanbaru \\
\hline Berat Volume Tanah & $\mathrm{t} / \mathrm{m}^{3}$ & 0,964 & 1 & 1,043 \\
Specific Gravity & & 1,381 & 1,439 & 1,52 \\
Angka Pori & & 6,891 & 8,166 & 11,090 \\
Kadar Air & $\%$ & 449,835 & 536,325 & 616,080 \\
Kadar Abu & $\%$ & 4,620 & 1,090 & 4,450 \\
Kandungan Organic & $\%$ & 95,380 & 98,910 & 95,550 \\
Kandungan Serat & $\%$ & 61,330 & 53,330 & 39,260 \\
-Serat Kasar & $\%$ & 49,690 & 35,350 & 38,880 \\
-Serat Medium & $\%$ & 31,940 & 35,840 & 32,120 \\
\hline
\end{tabular}


Lanjutan Tabel 1. Parameter tanah gambut di Indonesia

\begin{tabular}{ccccc}
\hline Parameter & Satuan & Banjarmasin & Palangkaraya & Pekanbaru \\
\hline -Serat Halus & $\%$ & 18,370 & 28,810 & 29 \\
Uji Vane Shear & $\mathrm{kPa}$ & 10,340 & 9,670 & - \\
Konsolidasi 1 tahap & $\mathrm{mm}$ & 5,1 & 5,8 & - \\
Klasifikasi & \multicolumn{4}{c}{ Gambut berserat (Hemic) dengan kandungan abu rendah } \\
\hline \multicolumn{5}{c}{ (Sumber: Mochtar N.E.) }
\end{tabular}

\section{Tiang pancang}

Fondasi merupakan bagian penting dalam sebuah konstruksi, salah satu jenis fondasi adalah fondasi dalam yang menggunakan tiang pancang. fondasi dalam adalah fondasi yang membutuhkan pengeboran atau pemancangan dalam karena lapisan tanah yang kerasberada di kedalaman cukup dalam, biasanya digunakan oleh bangunan besar, jembatan, struktur lepas pantai, dan sebagainya. Jenis fondasi dalam terbagi lagi menjadi dua, yaitu fondasi tiang dan fondasi bor. Tiang pancang merupakan salah satu contoh jenis fondasi tiang pada fondasi dalam. Penentuan jenis fondasi yang akan digunakan dipengaruhi beberapa faktor, diantaranya adalah kedalaman tanah keras, jenis tanah pada lokasi, dan beban yang akan dipikul oleh fondasi. Jenis tanah lempung (clay) dengan tanah keras yang terletak pada kedalaman yang dalam dan apabila beban yang harus dipikul fondasi besar sangat cocok digunakan fondasi tiang pancang sebagai pilihan dalam kontruksi bangunan. (Yusti \& Fahriani, 2014)

Penggunaan fondasi tiang pancang sebagai fondasi bangunan apabila tanah yang mempunyai daya dukung yang cukup untuk memikul berat bangunan dan seluruh beban yang bekerja berada pada lapisan yang sangat dalam dari permukaan tanah kedalaman > $8 \mathrm{~m}$ (Bowles, 1991). Pada kasus kali ini akan menggunakan tiang pancang sebagai fondasi dari jalan dikarenakan jalan dibangun diatas tanah gambut yang memiliki kekuatan daya dukung yang rendah.

\section{Soil replacement}

Teknik perbaikan tanah dengan metode penggantian tanah (soil replacement) merupakan salah satu metode tertua dan paling sederhana yang sering diterapkan dalam memperbaiki kondisi dan daya dukung tanah. Daya dukung fondasi dapat diperbaiki dengan mengganti tanah yang buruk (misalkan tanah organik atau tanah lempung lunak), dengan bahan yang lebih baik dengan kompeten seperti pasir, krikil atau batu pecah. Hampir semua tanah dapat digunakan sebagai bahan pengisi, namun beberapa jenis tanah yang sulit dipadatkan bila digunakan sebagai lapis pengganti.

Tanah lunak yang kompresibel dibuang, baik sebagian atau seluruhnya dan digantikan dengan material yang baik sperti ditunjukkan pada Gambar 2 dan Gambar 3. Pembuangan lapisan tanah lunak tersebut akan dapat menyelesaikan masalah stabilitas dan penurunan, karena timbunan diletakan pada lapisan yang lebih keras dan sebagaian besar penurunana akan dapat dihilangkan. (Muchlisin \& Roestaman, 2019)

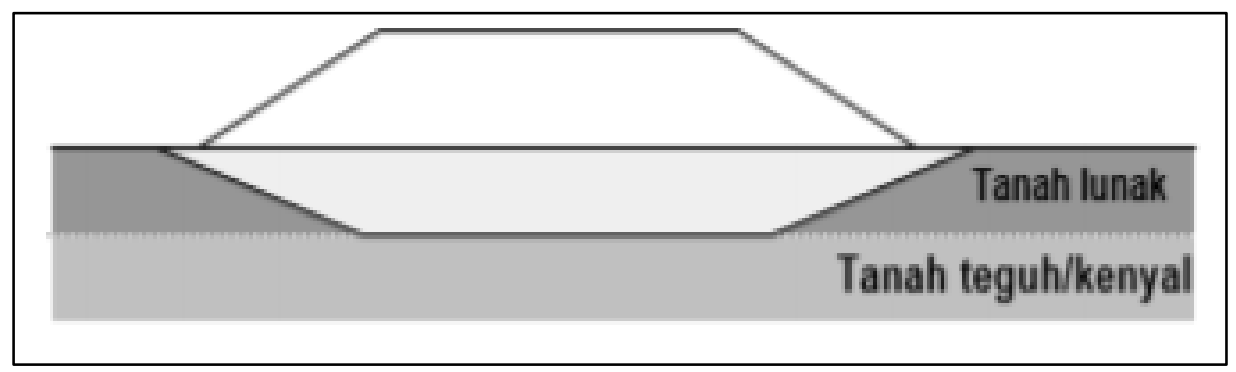

Gambar 2. Tanah pergantian total (Sumber: Muchlisin dan Roestaman, 2019) 


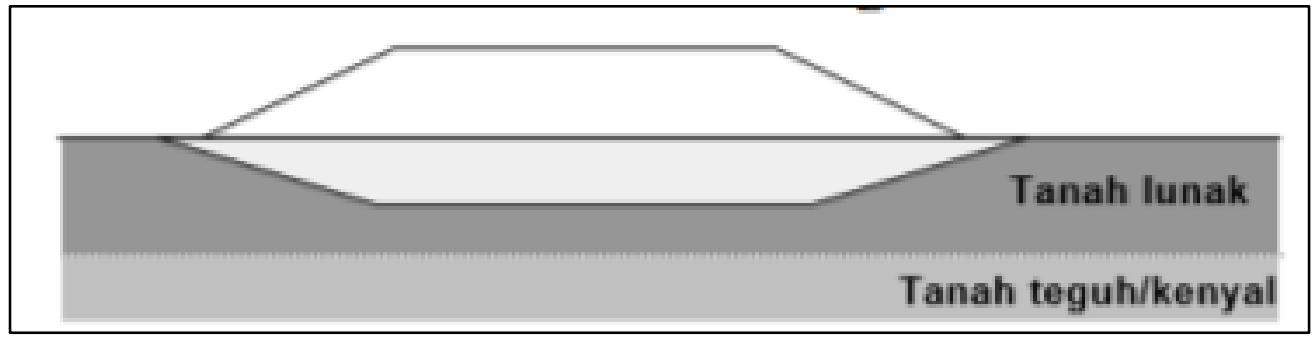

Gambar 3. Tanah pergantian sebagian (Sumber: Muchlisin dan Roestaman, 2019)

\section{METODE PENELITIAN}

Dalam penelitian ini dilakukan beberapa tahapan sebagai berikut :

1. Tahapan pertama, melakukan pengumpulan data data parameter tanah

2. Tahapan kedua, pengumpulan informasi yang berkaitan dengan tiang pancang dan metode soil replacement.

3. Tahapan ketiga, melakukan korelasi data pada parameter tanah dan pendekatan dari data-data yang ada dan dibutuhkan untuk memperhitungkan penurunan tanah jika menggunakan tiang pancang.

4. Tahapan keempat, melakukan analisis untuk penurunan yang terjadi jika menggunakan tiang pancang.

5. Tahapan kelima, penjabaran hasil dari kedua metode dimana dibandingkan metode mana yang lebih baik dari kekurangan dan kelebihannya masing-masing.

\section{HASIL DAN PEMBAHASAN}

Pada perencanaan menggunakan tiang pancang dengan jarak 2 meter antar tiang pancang dimana jalan selebar 12 meter. Menggunakan tiang pancang segi empat berukuran 400x400 mm dengan kedalaman hingga 14 meter dengan total penurunan 1,53 sentimeter. Metode soil replacement memperhitungkan jumlah volume yang akan digali dan ditimbun Kembali.

Tabel 2. Rangkuman parameter tanah

\begin{tabular}{ccccccc}
\hline Kedalaman $(\mathrm{m})$ & Jenis Tanah & N-SPT & $\gamma\left(\mathrm{kN} / \mathrm{m}^{3}\right)$ & $\Phi\left(^{0}\right)$ & $\begin{array}{c}\text { Es } \\
\left(\mathrm{kN} / \mathrm{m}^{2}\right)\end{array}$ & $\begin{array}{c}\mathrm{Cu} \\
\left(\mathrm{kN} / \mathrm{m}^{2}\right)\end{array}$ \\
\hline $0-2$ & HAI & 1 & 12 & 20 & 490,3 & 2 \\
$2-4,5$ & HAI & 1 & 13 & 20 & 490,3 & 3 \\
$4,5-8,5$ & HAI & 1 & 14 & 20 & 490,3 & 3 \\
$8,5-15$ & CH & 30 & 18 & 24 & 20000 & 200 \\
\hline
\end{tabular}

Pembebanan merata jalan diasumsikan sebesar $30 \mathrm{kN} / \mathrm{m} 2$ dan beban terpusat sebagai perhitungan negative skin friction pada program sebesar $3,84 \mathrm{kN} / \mathrm{m}$ sesuai dengan berat sendiri dari tiang pancang yang berukuran $400 \mathrm{x} 400$ $\mathrm{mm}$

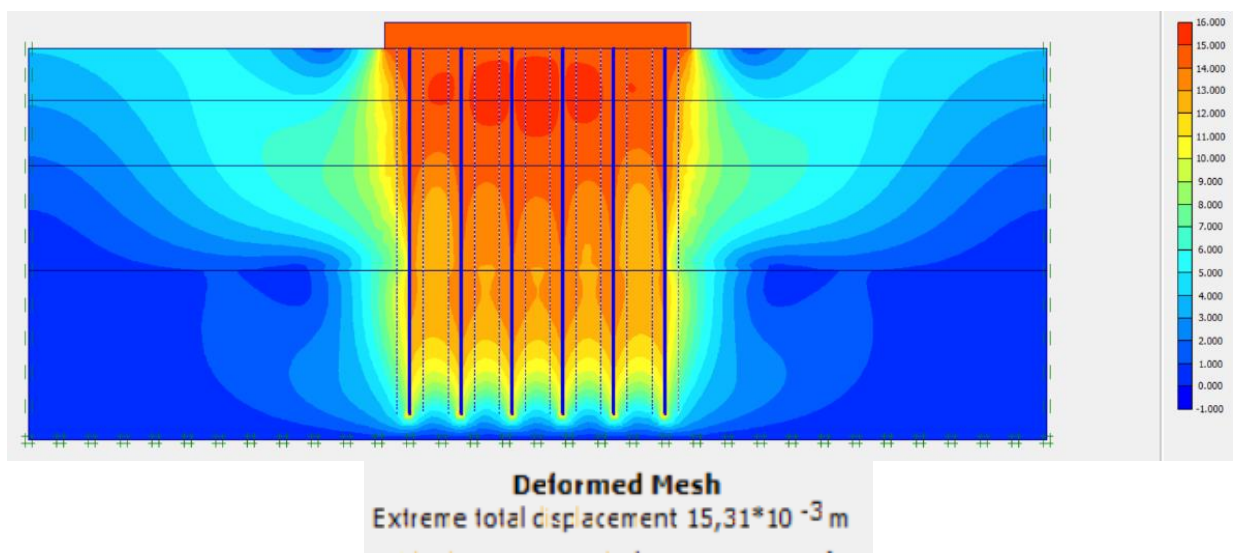

Gambar 4. Hasil penurunan tanah 
Dengan bantuan dari program PLAXIS $2 D$ didapatkan total penurunan jalan akibat beban yang sudah diperhitungkan sebesar 1,53 sentimeter dan untuk perhitungan volume jumlah tanah dihitung seperti berikut

Lebar jalan

Panjang Jalan diatas tanah gambut

Kedalaman tanah gambut

Total volume galian

$$
\begin{aligned}
& =12 \text { meter } \\
& =20 \text { meter } \\
& =9 \text { meter } \\
& =12 \times 20 \times 9 \text { meter } \\
& =2160 \mathrm{~m}^{3}
\end{aligned}
$$

Perhitungan diasumsikan tidak memperhitungkan sudut kemiringan tanah ketika digali dan ditimbun. Analisis perhitungan kedua harga metode tersebut dihitung dengan tabel berikut

Tabel 3. Perhitungan harga metode tiang pancang

\begin{tabular}{lcccc}
\hline & Jumlah & Satuan & Harga (Rp) & Total Jumlah Harga (Rp) \\
\hline Tiang Pancang & 840 & buah & 416.864 & 350.165 .760 \\
Jasa Pancang & 840 & Meter & 80.000 & 67.200 .000 \\
Pondasi Jalan & 240 & $\mathrm{M}^{3}$ & 860.000 & 206.400 .000 \\
\hline
\end{tabular}

Total harga menggunakan metode tiang pancang sejumlah Rp. 623.765.760. Harga soil replacement akan dihitung dengan cara berikut.

Tabel 4. Perhitungan harga metode soil replacement

\begin{tabular}{lcccc}
\hline & Jumlah & Satuan & Harga (Rp) & Total Jumlah Harga (Rp) \\
\hline Jasa Urug Tanah & 4320 & $\mathrm{~m}^{3}$ & 100.000 & 432.000 .000 \\
Sirtu & 2160 & $\mathrm{~m}^{3}$ & 220.000 & 475.200 .000 \\
\hline
\end{tabular}

Total harga pengurugan tanah kembali mencapai Rp. 907.200.000. Kedua harga tersebut terbilang berbeda jauh namun untuk metode tiang pancang, belum memperhitungkan harga coating dengan epoxy agar tiang pancang tahan dengan asam yang dikandung oleh tanah gambut.

\section{KESIMPULAN DAN SARAN}

\section{Kesimpulan}

Berdasarkan pengolahan data yang ada digunakan tiang pancang dengan variasi III dengan memancang tiang pancang sedalam 14 meter mengalami penurunan sebesasr 1,53 sentimeter.dengan ukuran tiang pancang 400x400 mm memakan biaya sekitar Rp. 597.600.000. dan untuk metode soil replacement memakan biaya sekitar Rp. 583.200.000. Hasil ini belum termasuk ongkos pemadatan tanah dan pembuatan fondasi jalan. Di kedua metode yang dilakukan harga yang didapat tidak terlalu jauh.

Diantara kedua metode tersebut memiliki kelebihan masing-masing dapat disimpulkan jika menggunakan metode tiang pancang pengerjaan dipastikan dapat lebih cepat dibandingkan dengan metode soil replacement. Untuk pekerjaan yang time sensitive seperti pembangunan jalan, metode tiang pancang diutamakan, selain pengerjaan lebih cepat biayanya bisa lebih murah jika dihitung waktunya. Namun untuk metode ini tidak menghilangkan sifat mudah terbakar tanah gambut.

\section{Saran}

Berikut adalah saran yang diperlukan agar membuat makalah ini lebih baik, untuk perencanaan tiang pancang dapat mendapatkan data tanah yang lebih memadai dan lengkap. Sehingga, ketika memperhitungkan tanah dengan program tidak mengasumsikan kekuatan tanah. Perhitungan harga dicoba untuk lebih mendetail seperti harga ongkos kirim, jasa pemadatan tanah, hingga biaya pekerja dan lainnya. Perlunya dicantumkan harga epoxy untuk melapisi tiang pancang agar dapat menahan sifat asam dari tanah. 
Analisis Alternatif Perancangan Desain dalam Fendy Hartano, et al.

Pembangunan Jalan di Atas Tanah Gambut

\section{DAFTAR PUSTAKA}

Dariah, Ai, Eni Maftuah dan Maswar. Karakteristik Lahan Gambut. Bogor, 2011

Bowles, J.E. Analisa Dan Desain Pondasi Jilid 1. Jakarta: Erlangga, 1991.

Jelisic, N. and M. Leppanen. Mass Stabilization of Peat in Road and Railway construction. 2001.

Muchlisin, Taufik and Roestaman. Analisis Stabilitas Timbunan Dengan Geotextile Woven. Garut, 2019.

Yulianto, F.E. and N.E. Mochtar. Mixing of Rice Husk Ash (RHA) and Lime For Peat Stabilization. 2010.

Yusti, Andi and Ferra Fahriani. Analisis Daya Dukung Pondasi Tiang Pancang. 2014. 